
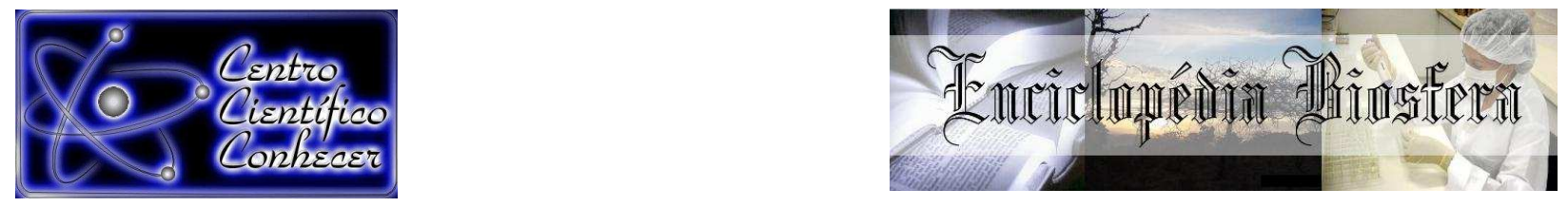

\title{
EVOLUÇÃO DO PROGRAMA GARANTIA SAFRA NO ESTADO DA BAHIA E NO TERRITÓRIO DE IDENTIDADE SUDOESTE BAIANO
}

\section{Carla Simone Araújo Gomes Sarmento ${ }^{1}$; Douglas Gonçalves Guimarães²; Eduardo Barreto de Castro Filho ${ }^{3}$}

${ }^{1}$ Bacharel em Engenharia Agronômica pela Universidade Estadual do Sudoeste da Bahia - UESB e Técnica de Nível Superior da Coordenação de Desenvolvimento Agrário - CDA. (carlasimonne@hotmail.com), Vitória da Conquista - Brasil.

${ }^{2}$ Bacharel e MSc em Engenharia Agronômica pela Universidade Estadual do Sudoeste da Bahia - UESB e Técnico de Nível Superior da Superintendência Baiana de Assistência Técnica e Extensão Rural - BAHIATER.

${ }^{3}$ Bacharel em Engenharia Agronômica pela Universidade Estadual do Sudoeste da Bahia - UESB e Técnico de Nível Superior da Superintendência Baiana de Assistência Técnica e Extensão Rural - BAHIATER.

Recebido em: 08/04/2016 - Aprovado em: 30/05/2016 - Publicado em: 20/06/2016 DOI: 10.18677/Enciclopedia_Biosfera_2016_055

\begin{abstract}
Este artigo analisa a evolução do Programa Garantia Safra no Território Sudoeste Baiano e no Estado da Bahia. Para tanto, foram coletados dados a partir de pesquisa no sítio eletrônico do Ministério do Desenvolvimento Agrário - MDA referente aos agricultores familiares aderidos ao Programa Garantia Safra durante as safras 2007/2008 a 2015/2016 do estado da Bahia e do Território de Identidade Sudoeste Baiano, que compreende os municípios de Anagé, Aracatu, Barra do Choça, Belo Campo, Bom Jesus da Serra, Caetanos, Cândido Sales, Caraíbas, Condeúba, Cordeiros, Encruzilhada, Guajerú, Jacaraci, Licínio de Almeida, Maetinga, Mirante, Mortugaba, Piripá, Planalto, Poções, Presidente Jânio Quadros, Ribeirão do Largo, Tremedal e Vitória da Conquista. Conhecer os dados do Programa Garantia Safra permite fazer uma análise quali-quantitativa da atuação desta política pública, sua contribuição e cumprimento dos objetivos esperados. Através desta pesquisa, conclui-se que o Programa Garantia Safra aumentou consideravelmente o número de adesões nos últimos anos no Estado da Bahia e no Território Sudoeste Baiano. Este Território conseguiu abranger todos os municípios na safra 2015-2016. Adesões importantes iniciadas a partir de 2011 constituiu feito importante para a sobrevivência do homem no campo durante uma das maiores secas do último século. $\mathrm{O}$ aumento de aderidos demonstra, em contrapartida, a fragilidade em que se encontra a produção e a baixa renda do agricultor familiar.
\end{abstract}

PALAVRAS-CHAVE: Agricultura familiar, Desenvolvimento Rural Sustentável, Território Identidade. 


\title{
EVOLUTION OF THE GARANTIA SAFRA PROGRAM IN THE STATE OF BAHIA AND IDENTITY TERRITORY SUDOESTE BAIANO
}

\begin{abstract}
This article analyzes the evolution of the Garantia Safra Program in the Territory Sudoeste Baiano and in the State of Bahia. Therefore, data were collected from research on the website of the Ministério do Desenvolvimento Agrário - MDA related to family farmers adhered to the Program Garantia Safra during the crop 2007/2008 to 2015/2016 of Bahia and Identity Territory Sudoeste Baiano, comprising the municipalities of Anagé, Aracatu, Barra do Choça, Belo Campo, Bom Jesus da Serra, Caetanos, Cândido Sales, Caraíbas, Condeúba, Cordeiros, Encruzilhada, Guajerú, Jacaraci, Licínio de Almeida, Maetinga, Mirante, Mortugaba, Piripá, Planalto, Poções, Presidente Jânio Quadros, Ribeirão do Largo, Tremedal and Vitória da Conquista. Knowing the Garantia Safra Program data allows a qualitative and quantitative analysis of the role of this public policy, their contribution and achievement of the expected goals. This territory could cover all municipalities in the 2015-2016 harvest. Through this research, it is concluded that the Garantia Safra Program significantly increased the number of accessions in recent years in Bahia State and Territory Sudoeste Baiano. Important adhesions in the State and Territory occurred from 2011, which is important for the survival of man in the field during one of the worst droughts of the last century. Increased adhesions shows, however, the weakness of which is the production and low-income family farmer.
\end{abstract}

KEYWORDS: Family Farming, Sustainable Rural Development, Territory Identity.

\section{INTRODUÇÃO}

Embora tardiamente, se comparada à tradição dos estudos sobre esse tema nos países desenvolvidos, a emergência da expressão "agricultura familiar" surgiu no contexto brasileiro a partir de meados da década de 1990. A incorporação e a afirmação da noção de agricultura familiar mostrou-se capaz de oferecer guarita a um conjunto de categorias sociais, como, por exemplo, assentados, arrendatários, parceiros, integrados à agroindústrias, entre outros, que não mais podiam ser confortavelmente identificados com as noções de pequenos produtores ou, simplesmente, de trabalhadores rurais (SHNEIDER, 2003). Com muitas conquistas a partir desta trajetória, a agricultura familiar ganhou forças nas políticas públicas, movimentos sociais e discussões acadêmicas em todos os âmbitos federativos.

A dinâmica agropecuária brasileira é dividida em diversas formas básicas de organização do espaço agrário podendo citar a disparidade entre a agricultura familiar e a agricultura latifundiária. Desde a época das capitanias hereditárias os latifúndios foram beneficiados por políticas públicas (FERNANDES et al., 2009). Dentre os acontecimentos mais marcantes que ocorreram na esfera das políticas públicas para o meio rural brasileiro, pode-se destacar a criação do Programa Nacional de Fortalecimento da Agricultura Familiar (PRONAF), que representa 0 reconhecimento e a legitimação do Estado, em relação às especificidades de uma nova categoria social - os agricultores familiares - que até então era designada por termos como pequenos produtores, produtores familiares, produtores de baixa renda ou agricultores de subsistência (SCHENEIDER et al., 2004).

$\mathrm{Na}$ Bahia, existem 665 mil estabelecimentos rurais da agricultura familiar, segundo o último censo agropecuário do IBGE, ocorrido em 2006, e de acordo o 
censo demográfico de $2010,28,57 \%$ da população baiana situa-se na zona rural (IBGE, 2016), constituindo a maior população rural dos Estados do Brasil. Dessa forma, os programas de fortalecimento da agricultura familiar são essenciais para o fortalecimento das economias locais, promoção do desenvolvimento rural sustentável e manutenção desta população expressiva no campo. Para tanto, recentemente com a Lei estadual № 13.204, de 11 de dezembro de 2014, foi criada a Secretaria de Desenvolvimento Rural - SDR, com políticas direcionadas às questões agrárias e a agricultora familiar (BAHIA, 2014), com o intuito de melhorias na vida do agricultor familiar do estado da Bahia.

Atualmente o Estado da Bahia está regionalizado por Territórios de Identidade, fruto de um processo que começou em 2003 e culminou em 2007 com a nova divisão regional do Estado, visando à articulação das políticas estaduais no âmbito das diversas secretarias, a partir de uma mesma regionalização. Inspirada no modelo adotado em 2003 pelo Ministério do Desenvolvimento Agrário (MDA) para o território nacional (MONTEIRO \& SERPA, 2011), que permanece até o presente momento.

O Território de Identidade Sudoeste Baiano, anteriormente com nomenclatura de Território de Identidade Vitória da Conquista, possui nova configuração, com vigência a partir de 2016, quando entrou em vigor o Plano Plurianual Participativo (PPA) 2016-2019, aprovado e sancionado pela Lei no 13.468, de 29 de dezembro de 2015 (BAHIA, 2015). Os municípios deste território estão incluídos na região semiárida (EMB, 2013), portanto, são vulneráveis aos efeitos da estiagem e contemplados com o Programa Garantia Safra.

O Estado da Bahia abrange três biomas, caatinga, cerrado e mata atlântica, sendo o Território Sudoeste Baiano inserido, quase totalmente, no bioma caatinga. Dessa forma, a área possui alta vulnerabilidade climática, sujeita a longos períodos de estiagem, conforme consta nos históricos meteorológicos. A marcante variabilidade interanual da pluviometria, associada aos baixos totais anuais pluviométricos, sobre a Região Nordeste do Brasil, é um dos principais fatores para a ocorrência dos eventos de "secas" sobre a região (NOBRE \& MELO, 2001).

A política pública do Garantia Safra foi instituída através da Lei no 10.420/2002, que criou o fundo financeiro e regulamentou o benefício, um projeto do Programa Nacional de Fortalecimento da Agricultura Familiar (PRONAF), destinado ao público de agricultores familiares sujeitos a perdas da safra por fenômenos de estiagem ou excesso hídrico. Trata-se de um seguro da produção agrícola, uma forma de garantir aos produtores estabilidade e assegurar a produção das intempéries climáticas que comprometem mais de $30 \%$ da receita bruta esperada (GRISA \& WESZ JUNIOR, 2010).

Tem direito ao Benefício Garantia Safra os agricultores familiares cuja renda bruta familiar mensal não exceda a 1,5 salários mínimos, que aderiram ao Fundo Garantia Safra e sofreram perdas em razão de estiagem ou excesso hídrico, comprovada na forma do regulamento, de pelo menos $50 \%$ do conjunto da produção de feijão, milho, arroz, mandioca ou algodão (BRASIL, 2002, 2012).

O Programa Garantia Safra é uma política pública do Governo Federal, viabilizada a partir da adesão dos poderes públicos Estadual e Municipal, bem como o próprio agricultor. As contribuições anuais dos agricultores, em conjunto com as contribuições (aportes) dos Municípios e Estados, representam aproximadamente $10 \%$ do total de recursos previstos para o pagamento dos benefícios no Estado, enquanto que a União arcará com mais de $20 \%$ (BRASIL, 2004). 
A criação de Políticas Públicas para a convivência com o semiárido é de fundamental importância para a agricultura, principalmente a agricultura familiar e deve ser pensada e executada de forma organizada e participativa para que os efeitos da estiagem não sejam prejudiciais ao cidadão e nem a economia local (SANTOS et al., 2012).

Este artigo possui como objetivo analisar a evolução do Programa Garantia Safra no Território Sudoeste Baiano, assim como em todo o Estado da Bahia. Dessa forma, espera-se que o Programa Garantia Safra esteja influenciando positivamente na convivência do agricultor familiar com a seca e sua manutenção no campo.

\section{MATERIAL E MÉTODOS}

Para elaboração do artigo foram utilizados dados do MDA a partir de pesquisa no sítio eletrônico, na opção "Relatórios Públicos de implementação do Garantia Safra", fornecido pela Secretaria da Agricultura Familiar (SAF). Os dados são referentes aos agricultores familiares aderidos no Programa Garantia Safra durante as safras 2007/2008 a 2015/2016 do estado da Bahia e do Território de Identidade Sudoeste Baiano.

Para interpretação e discussão do artigo, uma tabela e um gráfico foram elaborados a partir de dados de unidades familiares da Bahia e do Território de Identidade Sudoeste Baiano, aderidos no Programa Garantia Safra, nas safras 2007/2008, 2008/2009, 2009/2010, 2010/2011, 2011/2012, 2012/2013, 2013/2014, $2014 / 2015$ e 2015/2016. Os dados da safra 2015/2016 estão incompletos no estado da Bahia, pois até a data de elaboração do artigo, a região 2 do estado, com época de plantio no inverno, não tiveram os valores fechados, ainda estavam em fase de processamento.

A Bahia é o quinto estado em extensão territorial do Brasil e o maior da região Nordeste, possuindo uma área de cerca de $565 \mathrm{mil} \mathrm{km}^{2}$. Segundo dados do censo demográfico do IBGE em 2010, o Estado possui uma população de pouco mais de 14 milhões de habitantes, sendo que destes, quase quatro milhões residem na zona rural, segundo o censo agropecuário 2006, possuindo 761 mil estabelecimentos agropecuários, $86 \%$ destes, ou seja, 665 mil estabelecimentos rurais foram declarados como pertencentes a agricultura familiar, quantidade mais expressiva do país (IBGE, 2016). Para facilitar a administração, o estado foi dividido em 27 Territórios de Identidade (Figura 1). 


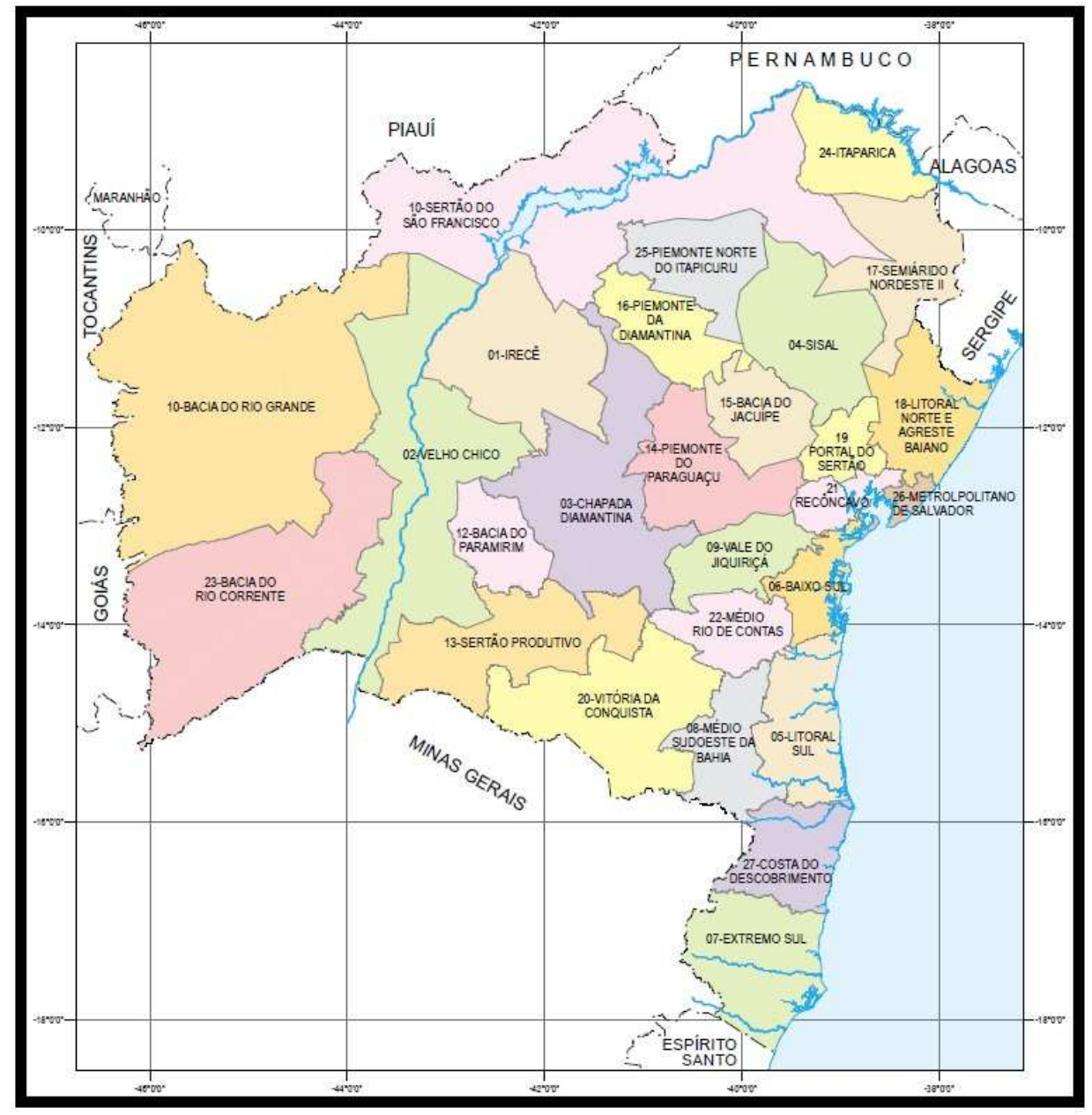

FIGURA 1. Mapa da Bahia com seus 27 Territórios de Identidade, incluindo Sudoeste Baiano (Vitória da Conquista).

FONTE: EMB, 2013.

O Território de Identidade Sudoeste Baiano, antigo Vitória da Conquista, inserido na macrorregião Semiárido, compreende uma área de $27.275,6 \mathrm{~km}^{2}$, equivalente a 4,7\% do território do estado, englobando 24 municípios (Figura 2) (BARRETO, 2014). O Território possui uma população estimada, segundo dados de 2010, de 695 mil habitantes, com destaque para o Município de Vitória da Conquista, com população estimada em 306 mil habitantes e com Produto Interno Bruto de $R \$$ 3,8 bilhões segundo IBGE, em 2013 (IBGE, 2016). No agronegócio regional, há destaque para as culturas agrícolas do café, algodão, maracujá, banana e também as culturas de subsistência como feijão, milho, mandioca etc. É importante considerar que a atividade pecuária se destaca com aproximadamente $70 \%$ de toda a área de cobertura vegetal do Planalto da Conquista (NOVAES et al., 2008). 


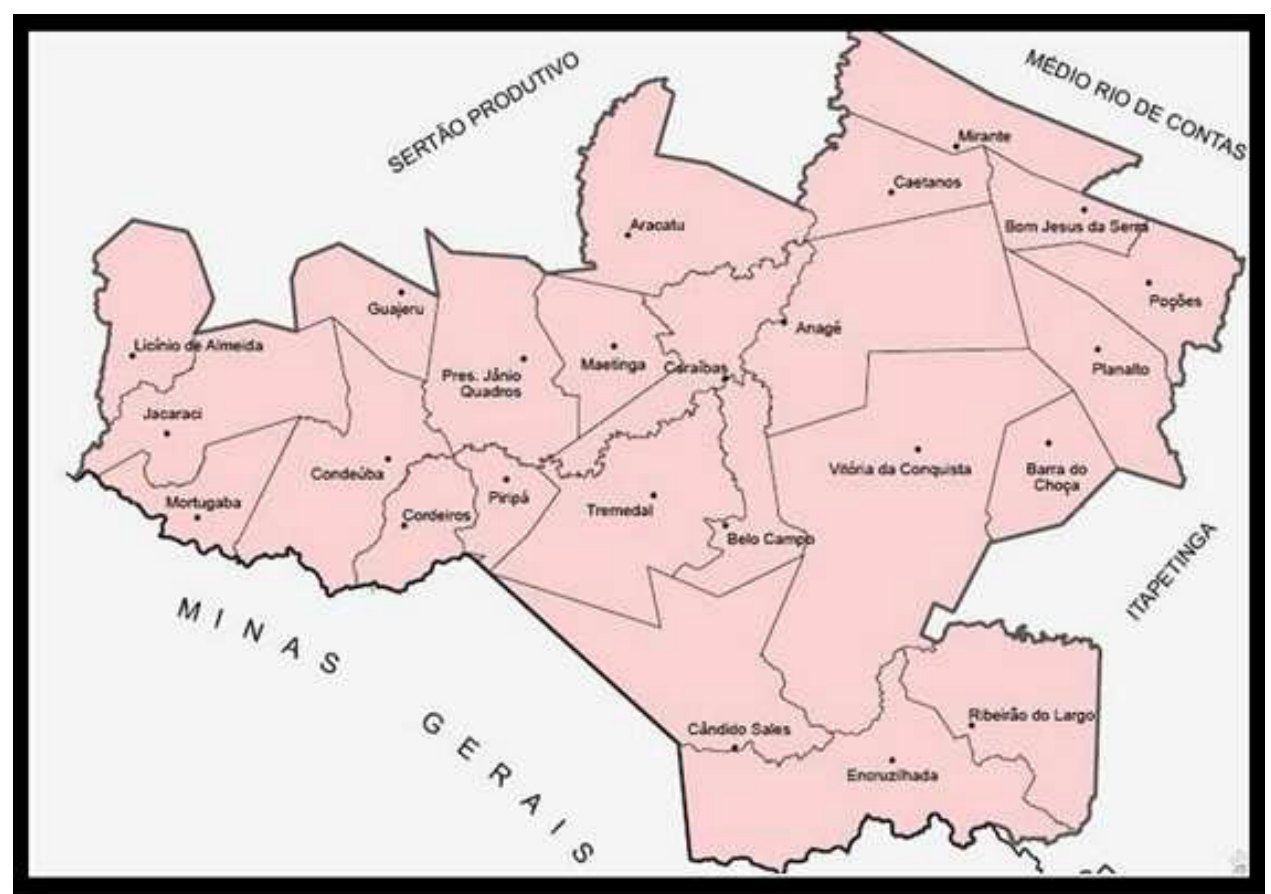

FIGURA 2. Território de Identidade Sudoeste Baiano e seus respectivos 24 munícipios abrangentes.

FONTE:

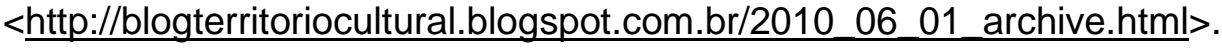

O Território está totalmente inserido no bioma Caatinga, com chuvas restritas a uns poucos meses durante 0 ano. O clima da região caracteriza-se por uma estação seca (maio a setembro) e outra chuvosa (outubro a abril) com precipitação pluviométrica média anual de 339 a 976 mm (EMB, 2013). Apesar da área ser cortada por uma razoável rede hidrográfica, parte desses rios são temporários, correndo apenas na época chuvosa. O conjunto de contrastes físicos e climáticos condiciona o aparecimento de diferentes tipos vegetacionais, muitas vezes na forma de um mosaico. A altitude diminui a temperatura local modificando a paisagem geral. Tal situação ocorre no Planalto da Conquista e em outras serras do Semi-árido, onde registram-se altitudes mais elevadas e maiores índices de pluviosidade. A disponibilidade de água é o fator mais determinante para a vegetação e a fauna, e até certo ponto para a exploração humana dos recursos naturais.

Além da pesquisa, para a interpretação e discussão dos dados foi fundamental também a experiência dos autores, que são profissionais da área agronômica, extensionistas da Secretaria de Desenvolvimento Rural - SDR do estado da Bahia, prestando assistência técnica no Serviço Territorial de Apoio à Agricultura Familiar (SETAF), em Vitória da Conquista, sede do Território de Identidade Sudoeste Baiano, atuando nos 24 municípios que são base para 0 estudo.

\section{RESULTADOS E DISCUSSÃO}

Conhecer os dados do Programa Garantia Safra permite fazer uma análise quali-quantitativa da atuação desta política pública, contribuição e cumprimento dos objetivos esperados no Território do Sudoeste Baiano. Os dados fornecidos no presente artigo são referentes ao Estado da Bahia e municípios do Território 
Sudoeste Baiano, com a finalidade de avaliar e comparar a evolução do Garantia Safra desde a implantação.

Nos relatórios de dados, fornecidos pelo MDA, a Bahia está subdividida em duas regiões, sendo a região 1 correspondente aos municípios que produzem durante a safra verão e a região 2 , durante a safra inverno. Isso se deve ao regime de chuvas no Estado ocorrer de forma sazonal e em períodos diferentes, devido a diversidade climática das regiões do Estado da Bahia. Sendo assim, os dados da região 2, não estavam disponíveis até a data da produção do artigo, tornando o dado da safra 2015/2016 incompleto.

O Território de Identidade Sudoeste Baiano, inserido nos dados da região 1, é composto por 24 munícipios, a primeira adesão ao programa Garantia Safra ocorreu na safra 2009/2010, com apenas quatro municípios, Condeúba, Cordeiros, Licínio de Almeida e Poções. Já na safra 2010/2011, ocorreu maior participação dos municípios, com aumento de $433,17 \%$ de aderidos e contemplando 58,33\% dos municípios do Território. Observa-se na Tabela 1.

TABELA 1. Evolução dos aderidos no Programa Garantia Safra no Território de Identidade Sudoeste Baiano e no Estado da Bahia no período das safras 2007/2008 a 2015/2016.

\begin{tabular}{|c|c|c|c|c|c|c|c|c|c|}
\hline \multirow[t]{2}{*}{ Município } & \multicolumn{9}{|c|}{ Período da Safra } \\
\hline & $\begin{array}{l}2007 / \\
2008 \\
\end{array}$ & $\begin{array}{l}2008 / \\
2009 \\
\end{array}$ & $\begin{array}{l}2009 / \\
2010\end{array}$ & $\begin{array}{l}2010 / \\
2011\end{array}$ & $\begin{array}{l}2011 / \\
2012\end{array}$ & $\begin{array}{l}2012 / \\
2013\end{array}$ & $\begin{array}{r}2013 / \\
2014 \\
\end{array}$ & $\begin{array}{r}2014 / \\
2015 \\
\end{array}$ & $\begin{array}{r}2015 / \\
2016 \\
\end{array}$ \\
\hline Anagé & - & - & - & - & - & - & 652 & 1.485 & 1.854 \\
\hline Aracatu & - & - & - & - & 262 & - & 899 & 1.416 & 1.680 \\
\hline Barra do Choça & - & - & - & - & - & - & - & 60 & 37 \\
\hline Belo Campo & - & - & - & 89 & 73 & 119 & 199 & 288 & 297 \\
\hline Bom Jesus da Serra & - & - & - & 579 & 663 & 874 & 1037 & 1.314 & 1.244 \\
\hline Caetanos & - & - & - & - & 96 & 214 & 877 & 1.051 & 1.445 \\
\hline Cândido Sales & - & - & - & 103 & 161 & 230 & 489 & 691 & 512 \\
\hline Caraíbas & - & - & - & 61 & 80 & - & 578 & 704 & 706 \\
\hline Condeúba & - & - & 192 & 271 & 305 & 423 & 1.113 & 1.271 & 1.399 \\
\hline Cordeiros & - & - & 176 & 296 & 413 & 575 & 806 & 914 & 897 \\
\hline Encruzilhada & - & - & - & - & - & - & 126 & 168 & 173 \\
\hline Guajeru & - & - & - & 87 & 58 & 68 & 475 & 721 & 760 \\
\hline Jacaraci & - & - & - & 455 & 629 & 988 & 1.761 & 1.678 & 1.848 \\
\hline Licínio de Almeida & - & - & 152 & 234 & 571 & 658 & 1.230 & 1112 & 1.170 \\
\hline Maetinga & - & - & - & - & 244 & 259 & 472 & 700 & 813 \\
\hline Mirante & - & - & - & - & - & - & - & 312 & 587 \\
\hline Mortugaba & - & - & - & 67 & 101 & 273 & 468 & 656 & 721 \\
\hline Piripá & - & - & - & 145 & 231 & 381 & 625 & 925 & 810 \\
\hline Planalto & - & - & - & - & 269 & - & 785 & 877 & 945 \\
\hline Poções & - & - & 89 & 8 & 509 & 864 & 1.467 & 1.613 & 1.774 \\
\hline $\begin{array}{l}\text { Presidente Jânio } \\
\text { Quadros }\end{array}$ & - & - & - & - & - & - & 744 & 1.112 & 1.178 \\
\hline Ribeirão do Largo & - & - & - & - & - & - & - & - & 68 \\
\hline Tremedal & - & - & - & 76 & 225 & 307 & 828 & 1.253 & 1.265 \\
\hline Vitória da Conquista & - & - & - & 167 & - & 326 & 519 & 1.407 & 1.337 \\
\hline TOTAL & 00 & 00 & 609 & 2.638 & 4.890 & 6.559 & 16.150 & 21.728 & $\begin{array}{r}23.52 \\
0 \\
\end{array}$ \\
\hline BAHIA & 14.988 & $\begin{array}{r}22.3 \\
39 \\
\end{array}$ & 64.117 & $\begin{array}{c}113.24 \\
5\end{array}$ & $\begin{array}{c}149.01 \\
4 \\
\end{array}$ & 203.550 & $\begin{array}{r}284.31 \\
9 \\
\end{array}$ & $\begin{array}{r}298.67 \\
4 \\
\end{array}$ & $\begin{array}{r}180.8 \\
33^{*} \\
\end{array}$ \\
\hline
\end{tabular}

*Dados incompletos devido à falta dos dados dos agricultores aderidos na safra inverno.

FONTE: BRASIL (2016). Disponível em:

(http://garantiasafra.mda.gov.br/GarantiaSafra/Relatorios/default.aspx?relatorio=24) 
O Programa Garantia Safra se tornou realidade no Território Sudoeste Baiano somente a partir da safra 2009/2010, embora os municípios do Estado da Bahia tenham iniciado a adesão na safra de 2007/2008. Na Tabela 1, observa-se a evolução dos municípios do Território Sudoeste Baiano aderidos ao Programa Garantia Safra. A primeira safra que os municípios do presente Território aderiram foi 2009/2010, contando com a adesão de quatro municípios (Condeúba, Cordeiros, Licínio de Almeida e Poções), nas safras posteriores houve aumentos consideráveis nos números de adesões. Na safra 2010/2011 houve adesão expressiva totalizando 14 municípios, 2011/2012, 17 municípios, 2012/2013, 21 municípios, 2013/2014, 23 municípios, culminando na safra 2015/2016 a adesão da totalidade dos municípios do Território. Os últimos a aderirem ao Programa foram Barra do Choça e Mirante, que se inscreveram apenas na safra 2013/2014 e Ribeirão do Largo, que na safra 2015/2016 logrou a primeira e única adesão deste município.

Analisando a Tabela 1, observa-se o considerável aumento de novas adesões no Programa Garantia Safra, tanto em municípios quanto em agricultores familiares, partindo de apenas quatro munícipios e 609 agricultores em 2009/2010 para todos os 24 munícipios e 23.520 agricultores na safra 2015/2016.

Avaliando, em números absolutos, os municípios que tiveram participação inexpressiva foram Barra do Choça, Encruzilhada e Ribeirão do Largo, representando juntos, apenas $1,18 \%$ de aderidos no Território. Esses municípios localizam-se na porção leste do sudoeste baiano, área de transição do bioma Caatinga e Mata Atlântica com microclima de altitude, que favorece o cultivo do café arábica, principal atividade desses municípios. Atribuindo portanto, a participação insignificativa, haja vista que as culturas subsidiadas pelo programa garantia safra são apenas milho, feijão, mandioca, algodão e arroz, além de outros pré-requisitos.

Observa-se ainda, que o número de aderidos no Território aumentou expressivamente na safra 2013/2014, podendo atribuir esse aumento às perdas ocorridas na longa estiagem da safra 2012/2013. A seca de 2012 causou prejuízo para os agricultores do Nordeste e perdura até o presente momento, referente a safra 2015/2016.

Segundo SANTOS et al. (2012), a seca na região Nordeste no ano de 2012 tomou proporções imensas, tão quanto as grandes secas já registradas no ano de 1777-1779 e a do ano de 1888 que ficou conhecida como "a seca dos três oitos" e de acordo com dados da Secretaria Nacional de Defesa Civil quase todos os município em todos os Estados da região Nordeste foram afetados de alguma forma pela estiagem.

A Figura 3, através de gráfico representativo, demonstra dois ciclos anuais com números de aderidos ao Garantia Safra, na Bahia e Território Sudoeste Baiano. É interessante notar que o máximo de movimento vertical ascendente ocorreu nos últimos anos de vigência do programa, certamente resultado do longo período de estiagem iniciado em 2012. Além disso, houve uma consolidação e divulgação do Programa nos Municípios, aumentando o número de aderidos. 


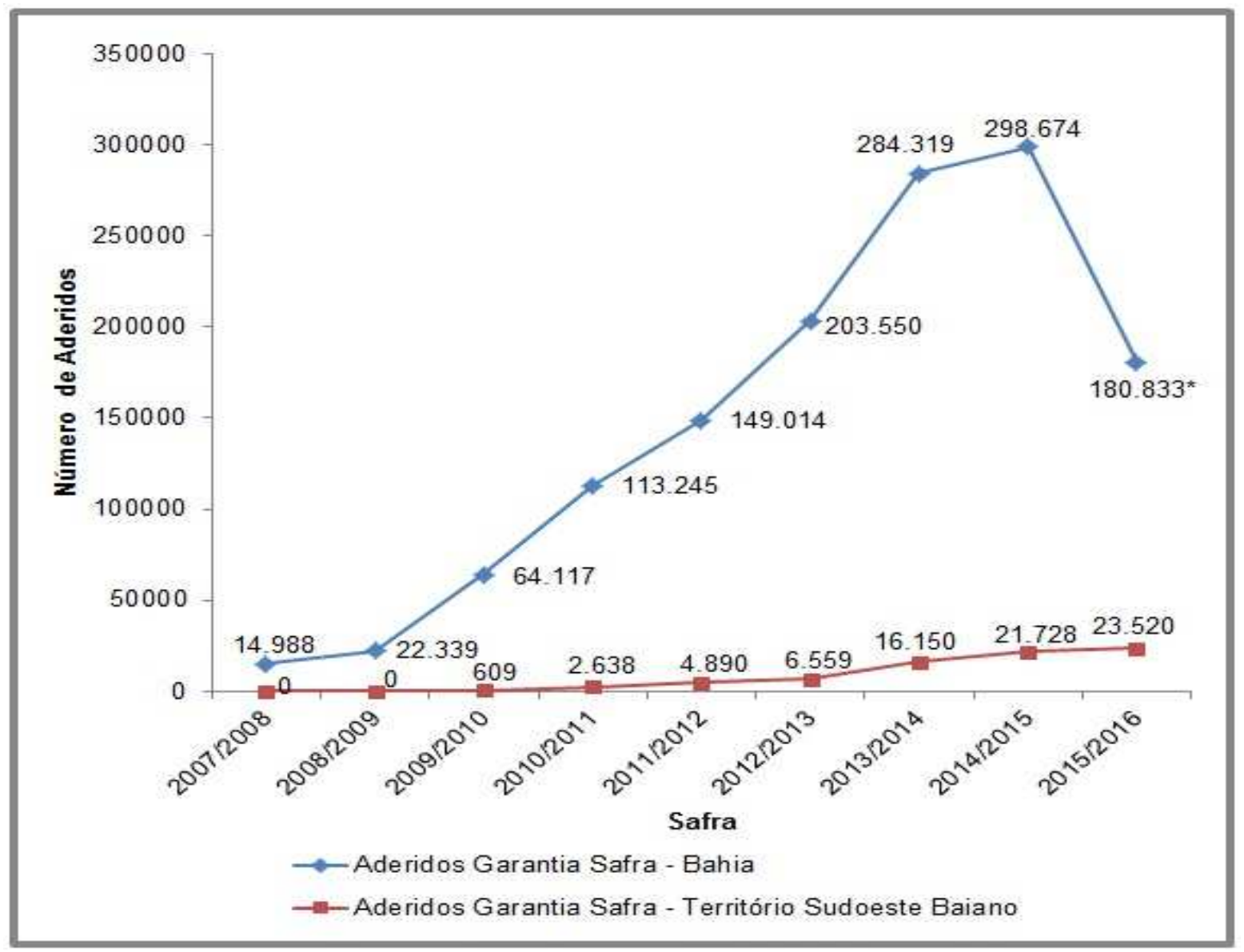

FIGURA 3. Evolução dos aderidos no Programa Garantia Safra no Território de Identidade Sudoeste Baiano e no Estado da Bahia no período das safras 2007/2008 a 2015/2016.

*Dados incompletos devido à falta dos dados dos agricultores aderidos na safra inverno.

FONTE: BRASIL (2016). Disponível em:

<http://garantiasafra.mda.gov.br/GarantiaSafra/Relatorios/default.aspx?relatorio=24>.

Nota-se ainda, nos dados da Bahia, que a safra 2015/2016 foi descendente, isso ocorreu devido a ausência de dados referente a safra inverno da região 1 , todavia, estima-se que na safra 2015/2016, após a consolidação dos dados das duas regiões, o número de adesões no estado fique em cerca de 300 mil agricultores familiares. A Bahia nos últimos anos vem ficando na segunda colocação entre os estados com maiores adesões no Programa, sendo superado apenas pelo Estado do Ceará (BRASIL, 2016).

Em âmbito Territorial, no Sudoeste Baiano, o número de aderidos ocorreu relevantemente a partir da safra 2013/2014, após perdas na safra 2012/2013 causada por mais uma seca iniciada neste ano e que perdura em 2015/2016. Até o momento tem-se um quadriênio de estiagem severa. Na maioria dos municípios do Território a base é a agropecuária, com produções de café, tomate, milho, feijão, banana, mandioca, algodão, bovinocultura e caprinocultura. No entanto, as culturas agrícolas não possibilitam uma produção agropecuária relevante, com exceção do café, pois são dependentes do período e distribuição de chuvas (BLATT \& GONDIM, 2013).

O aumento proporcional mais acentuado de adesões no Garantia Safra no Território Sudoeste Baiano, em relação ao ano anterior, foi observado na safra 
2010/2011, com incremento de 333,2\% em relação a safra 2009/2010, porém, o aumento mais significativo em números absolutos foi constatado na safra 2013/2014, com aumento de 9.591 adesões, partindo de 6.559 em 2012/2013 para 16.150 em 2013/2014. No Estado da Bahia, um significativo incremento foi observado em 2009/2010 (187\%) e em número de aderidos, o maior aumento foi na safra 2013/2014, partindo de 203.550 para 284.319, resultando em 80.769 novas adesões (FIGURA 3).

Presume-se então, que a política do Garantia Safra constitui aporte econômico significativo na economia, do Estado da Bahia e Território do Sudoeste Baiano, atuando como mitigador da perda econômica da produção de grãos causada pelas intempéries climáticas e como mantenedor do homem no campo, essencialmente nesse momento que vivem um quadriênio de secas sucessivas e perdas da produção agrícola, subsidiando o público mais fragilizado da agricultura.

Se comparado ao número de estabelecimentos agropecuários da agricultura familiar, referentes ao censo de 2006 (IBGE, 2016), aproximadamente 45\% dos agricultores familiares do Estado da Bahia estão aderidos e contemplados pelo programa Garantia Safra. Número bastante relevante que demonstra a fragilidade em que se encontram os estabelecimentos rurais da agricultura familiar do Estado, constituindo público empobrecido economicamente, com baixos rendimentos anuais, à mercê das intempéries climáticas, contabilizando altas perdas de produção e necessitado de apoio governamental para se manter no campo. Havendo necessidade de melhor aporte e assistência para esses estabelecimentos se estruturarem, enquanto agricultura familiar sustentável.

\section{CONCLUSÕES}

- O Programa Garantia Safra aumentou consideravelmente o número de adesões nos últimos anos no Estado da Bahia e no Território Sudoeste Baiano. Este Território conseguiu abranger todos os municípios na safra 2015-2016.

- Adesões importantes iniciadas a partir de 2011 constituiu feito importante para a sobrevivência do homem no campo durante uma das maiores secas do último século.

- O aumento de aderidos demonstra, em contrapartida, a fragilidade em que se encontra a produção e a baixa renda do agricultor familiar.

\section{REFERÊNCIAS}

BARRETO, M. B. Bahia 2000-2013. São Paulo : Editora Fundação Perseu Abramo, 2014. 152 p. (Estudos Estados Brasileiros). Disponível em: <http://www.fpabramo.org.br/publicacoesfpa/wp-content/uploads/2014/10/Bahiaweb.pdf>. Acesso em 04 de abril de 2016. 
BAHIA, Lei no 13.468, de 29 de dezembro de 2015. Disponível em: $<$ http://www.legislabahia.ba.gov.br/verdoc.php?id=83620>. Acesso em 24 de maio de 2016.

BAHIA, Lei no 13.204, de 11 de dezembro de 2014. Disponível em: $<$ http://www.legislabahia.ba.gov.br/verdoc.php?id=82114>. Acesso em 23 de maio de 2016.

BLATT, N.; GONDIM, P. S. C. Territórios de identidade no estado da Bahia: uma análise da regionalização implantada pela estrutura governamental na perspectiva do desenvolvimento local e regional. Colóquio Baiano Espaços, Tempos e Representações: Abordagens Históricas e Geográficas, v. 1, n. 1. 2013. Disponível em: <http://periodicos.uesb.br/index.php/coloquiobaiano/article/viewFile/2860/pdf_89>. Acesso em 22 de março de 2016.

BRASIL. Lei no 12.766, de 27 de dezembro de 2012. Disponível em: <http://www.planalto.gov.br/ccivil_03/_Ato2011-2014/2012/Lei/L12766.htm\#art6>. Acesso em 20 de Fevereiro de 2016.

BRASIL. Lei no 10.420, de 10 de abril de 2002 . Disponível em: <http://www.planalto.gov.br/ccivil_03/leis/2002/L10420a.htm>. Acesso em 12 de fevereiro de 2016.

BRASIL, Ministério do Desenvolvimento Agrário (MDA). Garantia-Safra: Orientações 2004-2005. Brasília: PRONAF/SAF/MDA, 2004. 32p.

BRASIL, Ministério do Desenvolvimento Agrário. Relatórios públicos de implementação do Garantia Safra. 2016. Disponível em: $<$ http://www.mda.gov.br/sitemda/secretaria/saf-garantia/relat\%C3\%B3rios-

p\%C3\%BAblicos-de-implementa\%C3\%A7\%C3\%A3o-do-garantia-safras. Acesso em 01 de fevereiro de 2016.

EMB, Estatísticas dos Municípios Baianos, Território de Identidade Vitória da Conquista, $\mathrm{n}^{\circ}$ 20, Salvador, v. 4, n . 1, 452 p., 2013.

FERNANDES, R. C; LOBÃO, J. S. B; VALE. R. N. C. Oeste baiano: da agricultura familiar à agroindústria. Encontros de Geógrafos da América Latina. Montevideo Uruguai. 2009. Disponível em: <http://www.bahiaflaneur.net/blog2/wpcontent/uploads/2010/08/agroindustrie.pdf>. Acesso em 15 de março de 2016.

GRISA, C.; WESZ JUNIOR, V. Políticas públicas para a agricultura familiar: entre avanços e desafios. Carta maior, 2010. Disponível em: <http://cartamaior.com.br/?/Opiniao/Politicas-publicas-para-a-agricultura-familiarentre-avancos-e-desafios-/22598>. Acesso em 10 de março de 2016.

IBGE (2016). Instituto Brasileiro de Geografia e Estatística. Sistema IBGE de Recuperação Automática - SIDRA. Disponível em: <http://www.sidra.ibge.gov.br>. Acesso em 05 de fevereiro de 2016. 
MONTEIRO, J; SERPA, A. Políticas de desenvolvimento territorial e cultural no território de identidade de Vitória da Conquista: uma análise geográfica da lógica de localização de projetos e recursos. Ateliê Geográfico, v. 5, n. 3, p.150-171, 2011. Disponível em: http://revistas.ufg.emnuvens.com.br/atelie/article/view/16983/10294 DOI: http://dx.doi.org/10.5216/ag.v5i3.16983. Acesso em 20 de fevereiro de 2016.

NOBRE, P.; MELO, A.B.C.. Variabilidade Climática intra-sazonal sobre o Nordeste do Brasil em 1998-2000. Revista Climanálise, CPTEC/INPE, 2001. Disponível em: $<$ http://mtc-

m16b.sid.inpe.br/col/cptec.inpe.br/walmeida/2003/07.04.16.36/doc/Nobre_Variabilida de\%20climatica.pdf>. Acesso em 12 de março de 2016.

NOVAES, A. B. de; LONGUINHOS, M. A. A.; RODRIGUES, J.; SANTOS, I. F. dos; GUSMÃO, J. C. Caracterização e demanda florestal da Região Sudoeste da Bahia. In: SIMPÓSIO SOBRE REFLORESTAMENTO NA REGIÃO SUDOESTE DA BAHIA, 2., 2005, Vitória da Conquista. Memórias. Colombo: Embrapa Florestas, 2008. p. 25-43. Disponível em:

<http://ainfo.cnptia.embrapa.br/digital/bitstream/item/132411/1/Livro.pdf\#page=22>. Acesso em 20 de março de 2016.

SANTOS, E., MATOS, H., ALVARENGA, J., SALES, M. C. L. A SECA NO NORDESTE NO ANO DE 2012: Relato sobre a estiagem na região e o exemplo de prática de convivência com o semiário no distrito de Iguaçu/Canindé-CE. Revista Geonorte, Edição Especial 2, v. 1, n. 5, p. 819 - 830, 2012. Disponível em: <http://www.revistageonorte.ufam.edu.br/attachments/013_\%28A\%20SECA\%20NO \%20NORDESTE\%20NO\%20ANO\%20DE\%202012\%20RELATO\%20SOBRE\%20A \%20ESTIAGEM\%20NA\%20REGI\%C3\%830\%20E\%200\%20EXEMPLO\%20DE\%20 PR\%C3\%81TICA\%20DE\%20CONVIV\%C3\%8ANCIA\%20COM\%20\%29.pdf>. Acesso em 22 de fevereiro de 2016.

SHENEIDER, S.; MATTEI, L.; CAZELA, A. A. Histórico, caracterização e dinâmica recente do PRONAF - Programa Nacional de Fortalecimento da Agricultura Familiar. In: SCHNEIDER, S.; SILVA, M. K.; MARQUES, P. E. M. (Org.). Políticas Públicas e Participação Social no Brasil Rural. Porto Alegre, 2004, p. 21-50. Disponível em: $<$ https://www.researchgate.net/publication/269576454_Historico_caracterizacao_e_d inamica_recente_do_Pronaf_-

_Programa_nacional_de_fortalecimento_da_agricultura_familiar>. Acesso em 25 de maio de 2016.

SCHNEIDER, S. Teoria social, agricultura familiar e pluriatividade. Revista Brasileira de Ciências Sociais, v. 18 n. 51, p. 99-121, 2003. Disponível em: <http://www.scielo.br/pdf/rbcsoc/v18n51/15988>. Acesso em 10 de fevereiro de 2016. 